microscopy. J Ultrastruct Res 26:31

21. Toma S, DiFerrante DT, Tenni R, DiFerrante N 1981 Preparation from keratan sulfate of substrates for the measurement of 2-actamido-2-deoxy-Dglucose 6 -sulfate sulfatase and $(1 \rightarrow 3)-N$-acetyl- $\beta$-D-glucosaminidase. Car- bohydr Res 88:93

22. Wilson D, Melnike E, Sly W, Marksbery WR 1982 Neonatal beta-glucuronidase deficiency mucopolysaccharidosis (MPS VII). J Neuropathol Exp Neurol $41: 344$

\title{
Microvillus Membrane Differentiation: Quantitative Difference in Cholera Toxin Binding to the Intestinal Surface of Newborn and Adult Rabbits
}

\author{
J. L. BRESSON, K. Y. PANG, AND W. A. WALKER \\ Pediatric Gastrointestinal and Nutrition Unit, Massachusetts General Hospital and the Pediatric Department, \\ Harvard Medical School, Boston, Massachusetts, 02114
}

\begin{abstract}
Summary
Microvillus membranes (MVM) were isolated from newborn and adult New Zealand rabbit small intestine. The isolation procedure provided a mean enrichment of $25 \pm 4$ for sucrase activity in adult preparations and of $27 \pm 3$ for lactase activity in newborn preparations. These purified MVM were incubated with increasing concentrations of ${ }^{125} \mathrm{I}$-labeled cholera toxin (CT). ${ }^{125} \mathrm{I}$ CT binding to adult MVM reached saturation at $6.4 \times 10^{-9} \mathrm{M}$; in contrast ${ }^{125} \mathrm{I}-\mathrm{CT}$ binding to newborn MVM did not reach saturation but instead continued to increase with increasing ${ }^{125} \mathrm{I}-$ CT concentrations. Scatchard plot analysis of adult data supported the existence of a single binding site $\left(K_{d}=1.2 \pm 0.2 \times\right.$ $10^{-9} \mathrm{M}$ ); analysis of newborn data, however, suggested the existence of additional binding sites, as ${ }^{125} \mathrm{I}-\mathrm{CT}$ binding to newborn MVM was inhibited by preincubation with unlabeled CT. These results show that $\mathrm{CT}$ binding to both preparations is quantitatively different and is higher in newborn preparations. This difference may be accounted for by the existence of additional binding sites in newborn MVM preparations in contrast to the presence of only the unique receptor previously reported in adult MVM preparations.
\end{abstract}

\section{Abbreviations}

MVM, microvillus membrane

CT, cholera toxin

Hepes, 4-(2-hydroxyethyl)-1-piperazineethanesulfonic acid

In many species, the small intestines undergo important modifications during postnatal development such as structural changes of the epithelial layer (6) or changes in MVM enzymatic activities (25). These modifications are likely to induce, as a

\footnotetext{
Received March 9, 1983; accepted January 9, 1984.
}

Reprints requests may be addressed to J. L. Bresson, Service de Gastroenterologie Pediatrique et de Nutrition, Hopital des Enfants Malades, 149, Rue de Sevres, 75730 Paris Cedex 15, France.

This work was supported by Grants GM21700, HD12437, and AM16269, from the National Institute of Health. K. Y. P. is a Trainee in Gastrointestinal Research (T32-AM07191). result, changes in MVM surface properties that may be reflected by events such as the "closure" of macromolecular transport through the small intestine (24). Comparison of MVM surface properties between newborn and adult are not yet available. Indirect approaches, such as those of Extler and Branstrator (9), have been used to study the lectin-binding capacity of small intestine mucosa during postnatal development; however, examination of histologic preparations under light microscopic conditions does not allow for a more precise conclusion about MVM-binding properties to be made.

In order to study MVM surface property changes with differentiation, we designed an in vitro system using MVM vesicles purified from newborn and adult rabbit small intestine, and tested these vesicles for binding characteristics using a molecular probe with an extensively studied microvillus receptor.

\section{MATERIALS AND METHODS}

Microvillus membrane isolation was performed according to a modification (3) of the $\mathrm{Ca}^{2+}$ precipitation method (27). Fasted adult ( $n=8$; more than 8 weeks old) and newborn $(n=50 ; 12$ to $24 \mathrm{~h}$ of life) New Zealand rabbits (Margaret's Home Farm, Greenfield, MA) were sacrificed and the small intestines were removed and washed with cold saline. The following steps were carried out at $4^{\circ} \mathrm{C}$. Scrapings of the whole adult mucosa or 4-5$\mathrm{cm}$ pieces of opened newborn small intestines were homogenized in $300 \mathrm{mM}$ mannitol, $12 \mathrm{mM}$ Tris buffer at $\mathrm{pH} 7.4$, diluted 1:6, and filtered on a $40-\mu \mathrm{m}$ nylon mesh (Tetko, Elmsford, NY). $\mathrm{CaCl}_{2}$ was added to a final concentration of $10 \mathrm{mM}$. After 15 $\min$ on ice, homogenates were centrifuged at $2500 \times g$ for 15 min on a Beckman J21B centrifuge with a JS7.5 rotor. Supernatants were saved and centrifuged with a JA20 rotor at 28,000 $\times g$ for $30 \mathrm{~min}$, then suspended in $50 \mathrm{mM}$ mannitol, $1 \mathrm{mM}$ Hepes buffer at $\mathrm{pH} 7.4$, and centrifuged again. The pellets (crude preparation) were resuspended in $1 \mathrm{mM}$ Hepes buffer and applied on the top of 10 to $60 \%$ sucrose gradients (Sigma Co., St. Louis, MO) which were centrifuged at $64,000 \times g$ for $25 \mathrm{~min}$ on a Beckman L5-65 ultracentrifuge with a SW 28 rotor. Bands were removed from the top, diluted $1: 10$, centrifuged at $100,000 \times g$ for $60 \mathrm{~min}$ on a $50 \mathrm{Ti}$ rotor. Pellets (final preparation) were 


\section{MICROVILLUS MEMBRANE DIFFERENTIATION}

resuspended in distilled water. Proteins were assayed according to Lowry et al. (18); dissacharidase activities were according to Dahlqvist (8); organic phosphorus measurements were performed according to McClare (21), and used as an indirect assessment of membrane phospholipids, assuming that their mean molecular weight was 750; electron micrographs were done on final preparations either fresh or after Epon embedding according to Luft (19).

Kinetic studies were performed using purified CT obtained from Schwartzman Co. (Orangeburg, NY). After reconstitution in $0.25 \mathrm{M}$ sodium phosphate buffer, and filtration on Sephadex G-75 (Pharmacia), the toxin was labeled, using Bolton-Hunter reagent (2) and separated from free label by an additional gel filtration. Cholera toxin concentration was measured by spectrophotometry, assuming $\left.A\right|_{\mathrm{cm}} ^{\%}=11.42(16)$. The mean specific activity was $200 \mathrm{mCi} / \mu \mathrm{mol}$. Experiments were carried out as described by Cuatrecasas (7). A previous report (7) and preliminary experiments (30) showed that ${ }^{125} \mathrm{I}-\mathrm{CT}$ binding to MVM was complete within $10 \mathrm{~min}$ and irreversible. Samples of adult or newborn preparations ( $50 \mu \mathrm{g}$ of membrane protein) were incubated for $20 \mathrm{~min}$ at $37^{\circ} \mathrm{C}$ with $0.08,0.32,0.64,0.96,1.28,1.9$ and $2.56 \mathrm{pmol}$ of freshly prepared ${ }^{125} \mathrm{I}-\mathrm{CT}$ in a $0.2-\mathrm{ml}$ final volume. Samples were diluted 1:10 with cold buffer and immediately poured on EGWP 25 Millipore filters (Millipore, Bedford, MA) which were washed, dried, and counted in a Beckman Gamma 7000 gamma counter. For each experiment, at each concentration, controls were done in which microvillus membranes were replaced by the same volume of buffer; these controls were processed as described for samples and counted to determine the nonspecific binding of ${ }^{125} \mathrm{I}-\mathrm{CT}$ to filters. Inhibition studies were done by preincubating samples from either preparation, at $37^{\circ} \mathrm{C}$ with unlabeled CT for $10 \mathrm{~min} .{ }^{125} \mathrm{I}-\mathrm{CT}$ was then added and each sample was incubated for another $15 \mathrm{~min}$ at $37^{\circ} \mathrm{C}$; in this time interval, no exchange between labeled and unlabeled CT was observed (7). Student's $t$ test was used to compare newborn and adult data; values are given as mean \pm SD.

\section{RESULTS}

Purity of microvillus membrane preparation. Purification of microvillus membranes was monitored by assays of sucrase activity in adult preparations and lactase in newborn ones. The adult final preparation yielded $1.8 \pm 0.3 \%$ of the homogenate protein amount, with a mean enrichment factor of $25 \pm 4$ for sucrase activity. The newborn final preparation yielded $2.1 \pm$ $0.2 \%$ of the homogenate protein amount, with a mean enrichment factor of $27 \pm 3$ for lactase activity. Newborn microvillus membranes appeared to be lighter than adult ones on velocity gradients (density of 1.102 versus 1.150 ), the protein to phospholipid ratio was $6.35 \pm 0.26$ in adult final preparations as opposed to $2.7 \pm 0.5$ in newborn preparations $(p<0.001)$. Electron micrographs showed that membranes were present in the form of closed vesicles which displayed "knob-like" formation on their external side in adult preparation; vesicles from newborn preparations however did not demonstrate such an assymmetry (Fig. 1).
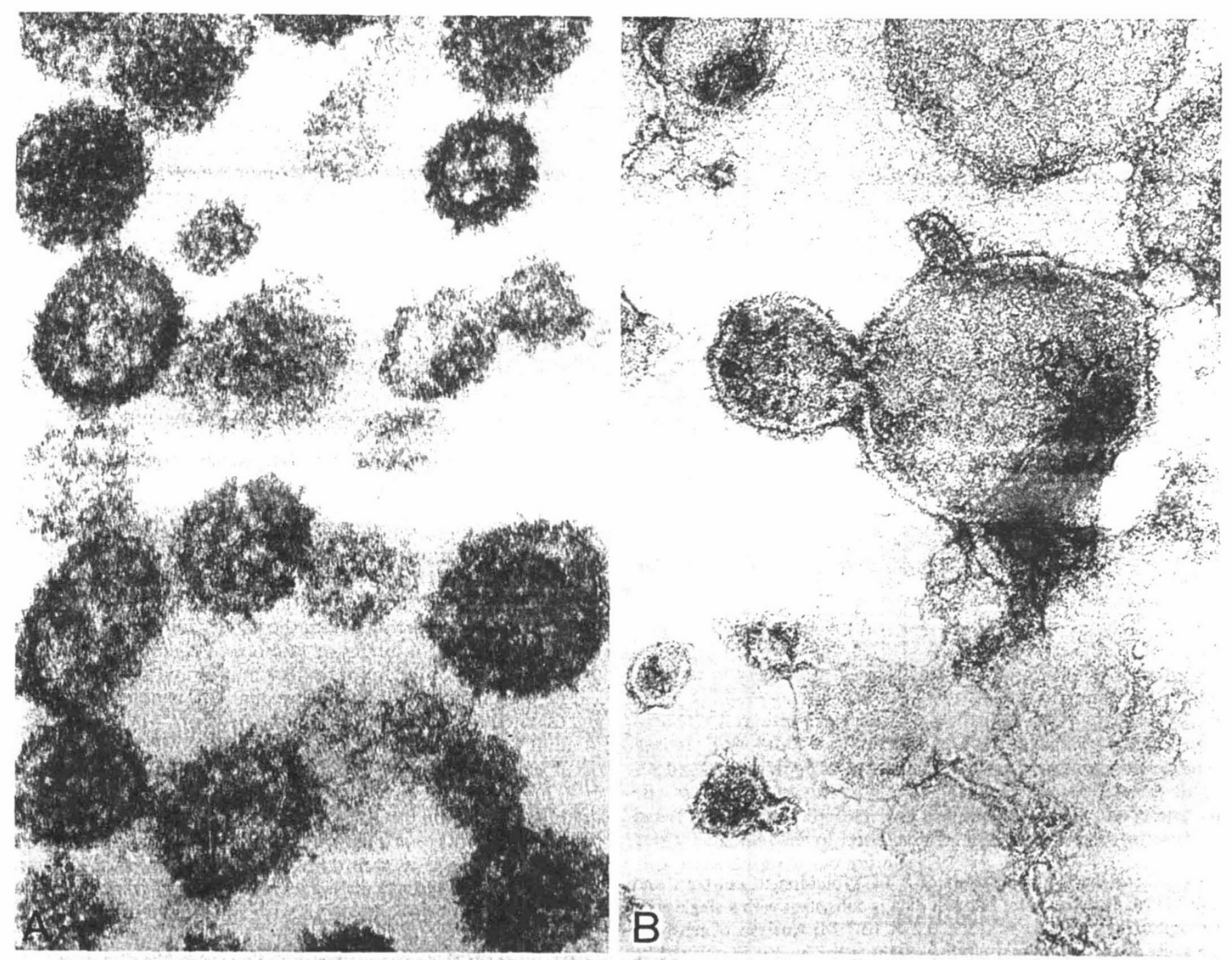

Fig. 1. A, electron micrographs of adult final MVM preparation after Epon embedding. $B$, negative staining of newborn final MVM preparation. 


\section{REFERENCES}

1. Auricchio S, Caporale C, Santamaria F 1981 Human fetal intestinal brush border sucrase, oligoaminopeptidase and dipeptidylaminopeptidase. Pediatr Res 15:1193

2. Bolton AE, Hunter WM 1973 Labeling of proteins to high specific radioactivities by conjugation to ${ }^{125} \mathrm{I}$-containing alkylating agent. Biochem $\mathrm{J}$ 133:529

3. Bresson JL, Pang K, Udall J, Fritze L, Walker WA 1980 Evidence for increased enterotoxin binding to newborn microvillus membranes. Gastroenterology 78:1145

4. Bresson JL, Walker WA 1981 Comparison of glycoprotein and glycolipids components of newborn and adult intestine microvillus membranes. Gastroenterology 80:1116

5. Bretscher MS 1973 Membrane structure. Science 181:622

6. Chambers C, Grey RD 1979 Development of the structural components of the brush border in absorptive cells of the chick intestine. Cell Tissue Res 204:387

7. Cuatrecasas P 1973 Interaction of Vibrio cholerae enterotoxin with cell membranes. Biochemistry 12:3547

8. Dahlqvist A 1964 Method for assay of intestinal disaccharidases. Anal Biochem 7:18

9. Extler ME. Branstrator ML 1979 Cell surface components and their relationship to cellular differentiation. In: Ciba Foundation (ed) Development of Mammalian Absorptive Processes, pp 51-62. Ciba Foundation, London

10. Gahmberg CG 1981 Membrane glycoproteins and glycolipids: structure, localization and function of the carbohydrate. In: Finean JB, Michell RH (eds) New Comprehensive Biochemistry, vol 1. Elsevier/North-Holland, Amsterdam. pp 151-159.

11. Galand G, Forstner GG 1974 Isolation of microvillus plasma membranes from suckling rat intestine: the influence of premature induction of digestive enzymes by injection of cortisol acetate. Biochem J 144:293

12. Glickman RM, Bonhours JF 1976 Characterization, distribution and biosynthesis of the major gangliosides of rat intestinal mucosa. Biochim Biophys Acta 424:17

13. Haase W, Schafer A, Murer H, Kinne R 1978 Studies on the orientation of brush border membrane vesicles. Biochem J 172:57

14. Hauser H. Howell K. Dawson RMC. Bowyer DE 1980 Rabbit small intestinal brush border membrane preparation and lipid composition. Biochim Biophys Acta 602:567

15. Lis H, Sharon N 1973 Biochemistry of plant lectins. Annu Rev Biochem
42:541

16. LoSpalluto JJ, Finkelstein RA 1972 Chemical and physical properties of cholera exo-enterotoxin (choleragen) and its spontaneously formed toxoid (choleragenoid). Biochim Biophys Acta 257:158

17. Louvard D, Maroux S, Baratti J, Desnuelle P, Mutaftschiev S 1973 On the preparation and some properties of closed membrane vesicles from hog duodenal and jejunal brush border. Biochim Biophys Acta 291:747

18. Lowry OH, Rosebrough NJ, Farr AL, Randal RJ 1951 Protein measurement with the Folin phenol reagent. J Biol Chem 193:265

19. Luft JH 1961 Improvement in epoxy resin embedding methods. J Biophys Biochem Cytol 9:409

20. Maestracci D 1976 Enzymic solubilization of the human intestinal brush border membrane enzymes. Biochim Biophys Acta 433:469

21. McClare CWF 1971 An accurate and convenient phosphorus assay. Anal Biochem 39:527

22. Miki K, Suzuki H, lino S, Oda T, Hirano K, Sigiura M 1977 Human foetal intestinal alkaline phosphatse. Clin Chim Acta 79:21

23. Morita A, Tsao D, Kim YS 1980 Identification of cholera toxin binding glycoproteins in rat intestinal microvillus membranes. J Biol Chem 255:2549

24. Morris IG 1968 Gamma globulin absorption in the newborn. In: Code CF (ed) Handbook of Physiology, Alimentary Canal, vol 2, pp 1491-1512 American Physiological Society, Washington, DC

25. Raul F, Simon P, Kedinger M, Haffen K 1977 Intestinal enzyme activities in isolated villus and crypt cells during post natal development of the rat. Cell Tissue Res 176:167

26. Scatchard G 1949 Attractions of proteins for small molecules and ions. Ann NY Acad Sci 51:660

27. Schmitz J, Preiser H, Maestracci D, Ghosh BK, Cerda JJ, Crane RK 1973 Purification of the human intestinal brush border membrane. Biochim Biophys Acta 323:98

28. Sillerud LO, Prestegard JH, Yu RK, Konigsberg WH, Schaffer DE 1981 Observation by ${ }^{13} \mathrm{C}$ NMR of interactions between cholera toxin and the oligosaccharide of ganglioside $\mathrm{G}_{\mathrm{M} 1}$. J Biol Chem 256:1094

29. Tsuboi KK, Schwartz SM, Burrill PH, Kwong LK, Sunshine P 1979 Sugar hydrolases of the infant rat intestine and their arrangement on the brush border membrane. Biochim Biophys Acta 554:234

30. Walker WA, Field M, Isselbacher KJ 1974 Specific binding of cholera toxin to isolated intestinal microvillus membranes. Proc Natl Acad Sci USA 71:320

\title{
Immune Response to Respiratory Syncytial Virus: Prevention of Syncytia Formation by Human Serum during in Vitro Infection
}

\author{
H. FADEN, T. LIN, J. J. HONG, AND P. L. OGRA \\ Division of Infectious Diseases and Clinical Virology, Department of Pediatrics, State University of New York, \\ Buffalo, New York 14222 and Taipei Medical College Hospital, Taipei, Taiwan
}

\section{Summary}

Human serum specimens containing respiratory syncytial virus (RSV)-specific neutralizing antibody were found to prevent the formation of syncytia when applied to HEp-2 tissue culture monolayers which had been infected with RSV $12 \mathrm{~h}$ previously. This was evidenced by the demonstration of RSV-infected cells

Received November 9, 1983; accepted December 27, 1983

Address correspondence to Howard Faden, M.D., Associate Professor of Pediatrics, Division of Infectious Diseases and Virology, Children's Hospital, 219 Bryant Street, Buffalo, NY 14222.

This work was supported in part by Public Health Service Grants AI-15939 from the National Institute of Allergy and Infectious Diseases, HL-21829 from the National Heart, Lung, and Blood Institute, and HD-15943 from the National Institute of Child Health and Human Development. without any syncytia formation in the monolayers treated with RSV antibody-positive serum. On the other hand, widespread syncytia formation was observed with antibody-negative control serum. The inhibitory effects of RSV antibody progressively declined when applied beyond $12 \mathrm{~h}$ after infection. Protection of the monolayer against syncytia formation occurred only in the presence of antibody and was quickly lost after the serum was removed. The titer of antisyncytial antibody correlated with the titer of neurtralization antibody.

\section{Abbreviations}

RSV, respiratory syncytial virus

CPE, cytopathologic effects 